\title{
Making Biology Count: Integrating Mathematics into the Teaching of Inheritance
}

\author{
Donna Satterthwait \\ University of Tasmania
}

\begin{abstract}
In this paper, I explore how seamless embedding of four mathematical concepts, counting, ratio, distribution, and statistical significance into a unit on inheritance enables students to gain a deeper insight into biological phenomena than a qualitative only approach achieves. The topic of Mendelian inheritance is used to illustrate this proposal. An introductory activity is presented that separates the specialized genetics vocabulary from the inheritance process, allowing the initial mathematical relationship to be developed and subsequently followed by the language requirements.
\end{abstract}

\section{KEYWORDS}

Biology education; Mendelian genetics; inheritance; mathematics in biology

Introduction. Although scientific literacy long has made significant inroads into the biological science classroom (Yore and Shymansky, 1991; Holliday, Yore and Alvermann, 1994), mathematical literacy has not, even at the tertiary level (Gross, 2004). In fact, many biology teachers avoid science content that requires mathematical understanding in addition to their biological discipline knowledge (Hartman and Glasgow, 2002; Šorgo, 2010). Increasingly, however, mathematical understanding is being applied at the research level in biological contexts to deepen knowledge about living systems. Mathematics has been integral in the conceptual development of the science of genomic sequences, for describing populations and key for pattern recognition in inheritance. Unfortunately, little of this understanding is shared in the secondary biology classroom.

Teaching advocates of quantitative biology have been attempting to link mathematical reasoning with biological understanding for the last forty years. As an undergraduate biology student, I was required to complete a year of calculus to qualify for a bachelor's degree in biology in the late 1960s: this subject was taught alongside, but not integrated into other undergraduate biology. Deliberate attempts to nurture this relationship have been largely unsuccessful or nonexistent (Aikens and Dolan, 2014); undergraduates study mathematics subjects, taught by mathematicians without biology backgrounds, 
and biology subjects are taught by biologists without mathematics backgrounds (Labov, Reid and Yamamoto 2010). The introduction of additional mathematics subjects will not solve the problem (Karsai and Kampis, 2010). As a result, these disciplines are seen as parallel, not intertwined, not as disciplines that enhance the study of each other.

There have been a few exceptions, usually occurring at the postgraduate level when students become engaged in their own research. However, even at this higher level, the mathematics are often seen either as models to be tested in biological contexts such as ecological modeling (e.g., the Lotka-Volterra models are based on logistic curves of abundance that can later be applied to a particular habitat), or in bioinformatics, involving comparative computer analysis, which check for similarities in gene or protein sequences.

Genetics. Probability and statistical analyses are commonly used in genetic studies. Gregor Mendel (1866), the father of inheritance studies, interbred pea plants, collecting data on their offspring's characteristics by counting how many individuals displayed particular attributes. Through the collection of numerical data for the seven traits observed, Mendel saw obvious patterns, usually expressed as ratios of the number of individuals with the traits over the total number of individuals. The mathematics arose from the biological phenomena and was used to help make sense of the data obtained. By recognizing the patterns, the key principles of independent assortment and segregation were defined. The mathematics evolved to explain the observed biology, the simple patterns of inheritance of traits. This more inductive approach provided considerable insight into biological understanding of inheritance. Perhaps if taught from an inductive perspective, students would better understand the process of the inheritance of traits.

Despite this close mathematical link from history, it seems that the application of the mathematics of genetics is more of a barrier than an aid to understanding today. The vocabulary associated with Punnett squares, hybridization, gamete formation, and tests of goodness of fit (e.g., chi-square), for example, routinely are applied to inheritance problems. Learning the vocabulary as well as the mathematics about this relationship simultaneously can be difficult. A quick google search of academic articles on this topic confirms the difficulty in learning genetics (e.g., Thomson and Stewart, 1985; Griffiths, 2008).

The problem. The topic of genetics is an integral part of secondary school biological sciences curriculum; secondary school biology textbooks commonly devote a significant proportion of their texts to the study of genetics. 
Finley, Stewart and Yarroch (1980) found in a survey of biology teachers that the teaching of genetics was considered to be a topic that is important to studying biology but is difficult for secondary school students to understand. A further study was carried out to determine why the topic is difficult. Stewart (1982) found that students attempted solving genetic problems with misconceptions and poor understanding of fundamental processes, most of these related to idiosyncratic use of Punnett squares (Stewart, 1982). In a survey published in 1999, one topic was identified by both secondary biology students and their teachers as being difficult - monohybrid and dihybrid crosses and linkages (Bahar, Johnstone and Hansell, 1999). A number of later studies also demonstrate the poor level of genetics understanding at the secondary school level (see Lewis and Wood-Robinson, 2000; Lewis and Kattmann, 2004; Kibuka-Sebitosi, 2007; Shaw, Van Horne, Zang and Boughman, 2008; Dougherty, 2009). Thirty years later than Stewart's study, Çimer (2012) again raised similar issues.

What happens today? Initial instruction in genetics occurs usually as a unit in a secondary school biology class, and although numerous resources, such as computer games and simulations, have been developed to aid the teaching of this subject, many secondary science teachers and their students still flounder.

This is not surprising because there is a number of studies that indicate that undergraduates at universities find this topic challenging despite having successfully completed tertiary mathematics and genetics subjects. Because of the challenges, 'active learning' and other pedagogic strategies have been recommended for more effective learning of genetics by university undergraduates (Smith and Wood, 2016). And yet, some new secondary biology teachers come into teaching with poor background knowledge in genetics despite passing their required undergraduate genetics subject (Chu, 2008; Smith and Knight, 2012).

The linking of mathematics with biology should be integrated as early as possible in schools (Karsai and Kampis, 2010; Šorgo, 2010). Others have proposed that modules that integrate introductory biology and quantitative skills should be required as part of the undergraduate degree (Hoffman, Leupen, Dowell, Kephart and Leips, 2016). In other words, unless improvements in the curriculum are widely instituted in ways suggested by the authors listed above, the ineffective teaching of genetics and its integration with mathematics will continue to be a multi-year, intergenerational problem.

Simply stated, genetics instruction in schools today is not effective for a variety of reasons. Despite mathematics being taught inside the genetics units, 
too many complex ideas are being delivered simultaneously to supposedly enhance understanding of the underlying concepts. When confronted with genetic problems, most students work through them as algorithms that are memorized in step-wise fashion as listed in their textbooks and by their teachers. Could this be changed to make learning more effective by focusing on understanding of the process? One possibility is to put greater emphasis on teaching the inheritance process first, examine the data generated, and then seek explanations and associated vocabulary.

A possible solution. Presented here is a classroom activity that offers a more inductive approach to the study of inheritance. The student instructions sheet, Inheritance Patterns, and the worksheet to this simulation activity can be found online as supplementary materials. For example, in this activity, the relationship of dominant and recessive alleles is derived by students noting that one allele has more 'power' than the other, and is, thus, observed to appear more frequently. Much of the inheritance process is discovered by the students themselves. The inheritance of two human traits is used as an example of the process of simple Mendelian inheritance, the ability to roll your tongue and the identification of the right or left-hand thumb being on top when you clasp your hands. Although the genetic basis of these two traits have been questioned (Patefield and Moore, 1986), students readily engage with these two traits because they can define the characteristics by rolling their own tongue or clasping their hands. The motivation factor is critical in focusing students on the process of inheritance, which many perceive as difficult to understand.

Below is a list of suggestions for the implementation of the Activity on the transmission of inheritable traits reproduced in the Appendix. The reader may find it useful to read the students' instructions for this activity before reading the lesson enactment suggestions.

(1) The cautious teacher may find it necessary to either work through genetic cross 1 step-by-step with the whole class or to do a preliminary cross of only one trait or both, i.e., tongue-rolling before having the students work in their pairs independently. This may take 30 minutes to complete.

The students then work through the activity as outlined in the instructions section (see Appendix). First, to determine what the parent looks like and draw the symbol in the box titled 'Appearance.'

Then each student in the pair flips the coin to see which of the two possible alleles are distributed to each offspring. For example, in cross $\mathbf{1}$, 
the father can donate either a can-roll-tongue allele or a cannot-rolltongue allele to offspring 1 . The student flips a coin to determine which allele is passed on. If the coin comes up heads, the can-roll allele is inherited; if the coin comes up tails, the cannot-roll allele is inherited instead.

The same procedure is carried out by the other student in the pair; however, in this instance, the mother's alleles are distributed.

The outcome is that offspring 1 will inherit one tongue-rolling allele from each parent: two alleles for this trait. When the offspring's inherited alleles are known, they should be written in the 'Genes' box on the worksheet.

After the combination of alleles are identified, the appearance of offspring 1 can be determined by referring to the Tongue Rolling Table. The students read the Tables on the instruction sheet to determine what the individual looks like.

Then the student pair repeats the procedure to determine the distribution of the alleles for hand-clasping. The student following the father notes that there are two possible alleles that can be given to offspring 1, either left-on-top allele or right-on-top allele. Again, a coin is flipped with heads giving the left-on-top allele and tails for the right-on-top allele to the offspring. The other student determines which of the two possible alleles will be given to offspring 1 from the mother.

Again, the two alleles (one from the father and one from the mother) needs to be written in the 'Genes' box. From this information, the offspring's appearance can be determined from Table 2 and the uppercase letter $\mathrm{R}$ or $\mathrm{L}$ can be recorded in the Appearance box.

(2) The students complete the 4 different dihybrid crosses that are defined by the large worksheet. To do this, the students need to follow the accompanying instruction sheet in pairs. After it is determined which student follows which parent, the students need to read the Appearance Tables 1 and 2 to determine what their parent looks like and write the symbol in the box on their worksheet under 'Appearance.'

In this way, the 'rules' for each student to follow one parent (one student follows the father and the other follows the mother) to produce offspring 
and flipping coins for the random distribution of alleles can be emphasized.

They will identify the two genetic traits, tongue rolling and hand clasping. Further scaffolding of this task may be required. See below.

(3) This introductory activity simulates hybrid crosses; data are generated by the students. Specifically, offspring are produced through random events initiated by students (i.e., flipping a coin), and these offspring can have different appearances. Variation in appearance of the offspring affords a comparison of the results obtained by different student groups despite being generated by identical initial crosses.

The generated data can be used to explain two key Mendelian genetic principles, that of independent assortment and segregation without the requirement for a new vocabulary. This also opens discussion of the relationship between meiosis, gamete formation and gene transmission.

(4) By counting the number of offspring with particular appearances, ratios can be calculated or plotted as simple histograms. This collated data is similar to that of Mendel's original data.

Randomness associated with coin flips and the resulting variation of offspring from identical crosses demonstrate how diversity is maintained through the parent/offspring generations; these data then can be used as a vehicle to explore variation patterns and other possible explanations, especially when the whole class data is amalgamated.

By student participation in this straight-forward activity, the key concepts of Mendelian inheritance are addressed. This exercise is not confounded with jargon. Nor is it presented first as a predicted/theoretical distribution, which is later applied to 'real' data through goodness of fit tests. This classroom activity approaches the learning of inheritance through analysis of data and serves as an introduction to the study of genetics. The activity also demonstrates how the use of simple, but authentic, mathematical relationships provide insight into the biological results.

Conclusion. After the introductory activity, further study can introduce vocabulary, the identification of gene relationships with and within chromosomes (mitosis and meiosis and linkage), non-Mendelian genetics and molecular correspondences. Punnett squares could be taught as an aid or tool to 
be used in elaboration of hybrid crosses after the key ideas of inheritance have been understood, rather than before. Regardless, many of these concepts can be referred back to the data originally generated in the introductory activity. This approach models a fundamental principle in science: that data serve as the check on theory. After all, the goal of studying science is to find explanations of what occurs in the natural world. In addition, in genetics, explanations for diversity within species or populations are the aim.

Variation is the conceptual bridge integrating the biological with the mathematical sciences. In the science of living things, variation is the underlying principle that makes natural selection and evolution possible. In mathematics, variation is the basis for the recognition of patterns: concepts, such as counting, ratio, distribution and statistical significance, allow for the arrangement of numbers to have meaning beyond digits. If variation and diversity are taught explicitly, greater melding of the two disciplines can occur, resulting in more meaningful use of mathematics in describing the reality of the biological world.

\section{Acknowledgements}

I would like to thank Dr Jane Watson for her useful suggestions in developing these ideas. 


\section{References}

Aikens, M. and E. L. Dolan. 2014. "Teaching quantitative biology: goals, assessments, and resources.” Molecular Biology of the Cell 25 (22): 3478-3481.

Bahar, M., A. H. Johnstone and M.H. Hansell. 1999. Revisiting learning difficulties in biology. Journal of Biological Education 33(2): 84-86.

Çimer, A. 2012. "What makes biology learning difficult and effective: Students' views.” Educational Research and Reviews 7(3):61-71.

Dougherty, M.J. 2009. "Closing the gap: Inverting the Genetics Curriculum to ensure an informed public.” American Journal of Human Genetics 85:17.

Finley, F.N., J. H. Stewart and W. Yarroch. 1982. “Teachers' perceptions of difficult and important science concepts for students to learn.” Science Education 66(4):531-538.

Griffiths, A. 2008. “Why do students find genetics so difficult to learn?” Paper presented at the XX International Congress of Genetics, Berlin, July 13.

Gross, L. J. 2004. "Points of View: The Interface of Mathematics and Biology.” Cell Biology Education 3(2): 85-87.

Hartman, H. J. and N. A. Glasgow. 2002. Tips for the Science Teacher:

Research-based Strategies to Help Students Learn. Thousand Oaks:

Corwin Press.

Hoffman, K., S. Leupen, K. Dowell, K. Kephart and J. Leips. 2016.

"Development and Assessment of Modules to Integrate Quantitative Skill in Introductory Biology Courses.” CBE_Life Science Education 15: 112.

Holiday, W. G., L. D. Yore and D. E. Alvermann. 1994. "The Reading-Science Learning-Writing Connection: Breakthroughs, Barriers, and Promises.” Journal of Research in Science Teaching 31 (9): 877-893. 
Karsai, I. and G. Kampius. 2010. “The Crosswords Between Biology and Mathematics: The Scientific Method as the Basis of Scientific Literacy.” Bioscience 60(8): 632-638.

Kibuka-Sebitosi, E. 2007. "Understanding genetics and inheritance in rural schools.” Journal of Biological Education 41(2):56-61.

Labov, J. B., A. H. Reid and K. R. Yamamoto. 2010. “Integrated Biology and Undergraduate Science Education: A New Biology Education for the Twenty-First Century?” CBE_Life Sciences Education 9 (1):10-16.

Lewis, J. and U. Kattmann. 2004. “Traits, genes, particles and information: Revisiting students’ understanding of genetics.” International Journal of Science Education 26(2):195-206.

Lewis, J. and C. Wood-Robinson. 2000. Genes, chromosomes, cell division and inheritance -Do students see a relationship?” International Journal of Science Education 22(2): 177-195.

Mendel, G. 1866. “Experiments in Plant-Hybridization.” [In German.] In Classic Papers in Genetics, edited by J. A. Peters, 1-20. Englewood Cliffs: Prentice-Hall.

Patefield, J. M. and M. L. Moore. 1986. "The Genetic Basis of Tongue Rolling.” Journal of Biological Education 20(4): 255-256.

Shaw, K. R., K. Van Horne, H. Zang and J. Boughman. 2008. "Essay context reveals misconceptions of high school students in genetics.” Genetics 178(3): 1157-1168.

Smith, M.K. and J.K. Knight. 2012. "Using the genetics concept assessment to document persistent conceptual difficulties in undergraduate genetics courses.” Genetics 191(1):21-32.

Smith, M. K. and W. B. Wood. 2016 "Teaching Genetics: Past, present and future.” Genetics 204 (1): 5-10.

Šorgo, A. 2010. "Connecting Biology and Mathematics: First Prepare the Teachers.” CBE_Life Science Education. 9(3):196-200. 
Stewart, J. H. 1982. "Difficulties Experienced by High School Students When Learning Basic Mendelian Genetics.” The American Biology Teacher 44(2): 80-89.

Thomson, N. and J. Stewart. 1985. "Secondary school genetics instruction: Making Problem Solving Explicit and Meaningful.” Journal of Biological Education 19(1):53-62.

Travis, K. 2011. CTSciNet. Career Profiles. doi: 10.1126/science.caredit.a1100039

Yore, L.D. and Shymansky, J.A. 1991. "Reading in Science: Developing an Operational Conception to Guide Instruction.” Journal of Science Teacher Education 2(2): 29-36. 
Satterthwait, D. (2018). Making biology count: Integrating mathematics into the teaching of inheritance. Journal of Biological Education, 53(1). DOI:10.1080/00219266.2018.1427613 